\title{
13 \\ Government online: Are we there yet?
}

Tamati Shepherd ${ }^{1}$

To answer the question 'are we there yet with government online?', I would argue vehemently that no, we're not there yet. In fact, I would assert that if you are in the business of digital government and you think we are 'there', it is time to retire. Because you are actually never 'there'. If you look closely at the true nature of digital transformation, we are being pulled, pushed and driven by consumer expectations and social movements; by developments in technology and by policy change that means we have a big agenda ahead of us.

Consequently, in my department, Human Services (DHS), we have started a process that we call internally 'meerkat' reviews. What that simply means is, like a meerkat, lift your head up, have a look around and ask yourself: has anything changed? And if it has, change direction. We started this process because, if you read what we started to do in our service delivery reform agenda seven years ago, we did not envisage smart phones and mobile at all.

1 This chapter was written when Tamati Shepherd was chief digital officer of Department of Human Services, and is relevant to that time. 
Thankfully, we consulted Gary Sterrenberg, the chief information officer (CIO) from ANZ bank, who pushed us in the right direction. He said the world was going mobile, that no one's going to have a desktop and that customers are not going to do business on a PC, but on their mobile. I thought he was crazy. But he was spot-on: mobile and digital has gone from about 5 per cent of our business to now being over 50 per cent. Had we stopped and done a meerkat review, we might have seen that coming. We were lucky we had a retail bank CIO who saw it coming and got us ready for it. This is a lesson for other public servants: convince your internal audit units what you should be doing is meerkat reviews. Our audit department is having a meltdown thinking about how they are going to assess us when we conduct these reviews.

The first point I wanted to make is not about public sector digital capacities but about our customers and the community. The fact is, consumer assumptions about the way consumers conduct their life are changing, and so are their expectations. In that regard, government is not isolated: increasingly, consumers want to do business with government digitally. So, what does that mean for us? First, it means we have needed to stop thinking like a government department and start thinking like a retail operation; our benchmark is to make dealing with us as easy as with a bank, so if you have had to apply for something recently you will know we still have a little way to go.

The second expectation is to be available $24 / 7$. We work very closely with our colleagues at the Australian Taxation Office (ATO) and in 2014, when we first launched myGov and myTax, we both realised that we cannot shut our call centres at $5 \mathrm{pm}$ on a Saturday or a Sunday when our new peak time is $8 \mathrm{pm}$ to $11 \mathrm{pm}$. That's now when families want to do business digitally with us. As a consequence, we had to reorganise ourselves, get our calls diverted to our 24-hour call centre so that if a customer has a problem at 10.30 at night, they will actually reach somebody who can help them with an assisted digital service.

The third expectation is immediate responses. On average, our customers are calling or coming in to see us four times after they have submitted a digital claim because they want immediate feedback about its progress. Gone are the days when customers will put up with waiting 21 days while their claim was assessed. 
Just like Domino's, where once you order a pizza you can track the order-received, being cooked, being delivered-we aim to do the same thing regarding claims. We are doing that with our customers because in the digital world, when a customer pushes the 'enter' button they expect an immediate response- even if our systems are not always set up to do that, nor are our staff paid to actually process at that sort of speed.

The fourth expectation we have found is that services need to be synced. When it comes to dealing with government in the digital world, customers don't care what level or brand or agency of government you're from. If they just want to change their address, they don't care whether you're from Queensland Health, Medicare or Human Services. They expect that once they change their address with one agency, every agency will know.

We are getting better at meeting this expectation. Nowadays, when we receive a change of address we can tell the Tax Office, we can tell Medicare, we can tell Centrelink. And we are working on synchronising other details like new licences. It is consumers driving this change: in the world of digital, their expectation is that everything is connected.

Moreover, there is a big shift underway with the launch of the Digital Transformation Office. It aims to be more user-centric, putting the customer experience first. The Queensland Government and Brisbane City Council have been leaders in this regard, looking at how this concept of the customer's experience needs to transcend all levels and all tiers of government. Because nowadays, when someone has a child they do not want to have to go five different places to do the things that they need to do around the birth of that child. The environment around customer expectations is changing. And from the Australian Government's perspective, the Digital Transformation Office is a symbol of this massive push to digital.

I will now recount our experience of these issues at DHS. The department has over 23 million customers, predominantly because we do Medicare payments, which touch nearly everybody in the Australian community. We make about 60 million phone calls a year, have about 1,000 service points ( 400 of them are ours and 600 of them are agents); we employ over 30,000 staff, and we shift about $\$ 160$ billion in Commonwealth money through the transfer system annually. This equates to about a third of the federal budget. 
In other words, when we tweak things we want to get them right, because there are big impacts when we make mistakes. As an organisation, in terms of our journey towards being better suited to the digital economy, we first went through a consolidation or amalgamation phase, where we brought all of the parts of the old organisations together under our umbrella. During that time, we did things fast: we built one finance system, one human resources system, one set of employment arrangements, a brand, a uniform for the staff, one-stop shops, and we got people co-training between Medicare and Centrelink and child support.

In the second phase, which is sometimes known as superciliary reform, we did a lot of work on integration. I want to point out a couple of things during that integration phase that provide interesting lessons in the digital space from the last four to five years. The first is the value of co-design. We spent a lot of money setting up a co-design capability in the department: the notion of designing services with our customers. And we keep getting better at doing that. It was a bit of a journey, but to give you some idea of the value that has in terms of digital, consider the example of our child support app.

If you are a child support recipient or payer, you are probably using it. How did we design it? We started it in Adelaide, where we asked our staff to brainstorm what would be the core thing we could do with a child support app, what would be of value to our customers. Basically, we tried to replicate what we were doing in the online PC space in an app. We mocked it up, we prototyped it and we took it to our customers and they said that is not what they wanted at all.

Initially we were adamant: we explained that it was simply what they were doing on a PC with us, just replicated in app form. And they said no, if government was going to use smart phones, they wanted the ability to be able to talk to each other via the app to make arrangements around shared care and a whole range of dialogue. Because, they said, if we have to do that on a government app, we will be nice to each other and, if you support that dialogue, and then do all the calculations you need to do about our child support arrangements, you can just get out of our way then and we will deal with that and only contact you when we need to.

In this way, the mode of the delivery reframed the service delivery model because when we put it in parents' hands, they saw the value of it being a bi-directional digital conversation between them and us. And now, we do 
what we need to do at the backend to make calculations and adjustments, only intervening when we absolutely need to. The whole experience was a good lesson in not assuming all the best ideas have to be in your own team. Because the customer actually has some smart ideas around how you might shape your products.

A second example I wish to share concerns an idea a junior employee had about wi-fi. He sent me a note about it through our ideas program. He explained that we want our customers to go digital, but we do not offer wireless for them. Our customers are some of the poorest people in Australia. They don't have data plans. They have no credit left on their phone and we wanted them to download an app. This APS4 employee simply requested we turn on the wireless for our customers. We have since gone through a rather tortuous process where we were granted permission from the security people to turn our wireless network on for our customers, allowing them to come in and use wi-fi. Our only concern is not to make this too attractive, whereby our offices would resemble a McDonald's, with lots of people going there simply to use the free wi-fi.

Another focus for innovation is the myGov shopfront, which complements the website. It arose almost by accident. The ATO had to get out of its shopfront in Brisbane. So did we. We thought, why don't we go digital together? Why don't we try and put an integrated service offer together? We had a vague idea, but not a detailed plan. We put butcher's paper up on the site and we got the staff and the customers to co-design the service delivery model. We are now a couple of years down the track. When you walk into that site, you don't know you're dealing with an ATO officer or a DHS person or a Medicare officer. It's all integrated.

When they visit the myGov shopfront, the customer experiences an integrated government service office where staff have been co-trained in each other's products. It was a case of being the house that Jack built: we had to make it up on the fly and organically grow it; from Brisbane it has now spread to Sydney, Adelaide and Perth, and in the process been refined. We iterated as we went, but if you were to ask us what was our blueprint for the myGov shopfronts, I'd have to resurrect the butcher's paper that was on the wall in Queensland because that's how we designed it. 
The next phase of our transformation is critically important. Because while we have done a lot of good digital work facing the customer, our backend systems do not support the delivery that we need going forward. We need to upgrade these backend capacities greatly.

In terms of some of our actual achievements, the numbers look good. While we still have plenty of work to do to improve our customer experience (you only have to look at social media to see that), two years after being established, the myGov website had 7.5 million users. This will only increase. My personal target is to overtake the Qantas frequent flyer program, which is the biggest membership-based organisation in Australia, at 10.1 million.

When we pass Qantas, we will know we have achieved a good critical mass. It is actually quite hard to predict what the end game number is because of the way people are entitled to different things and the way new members come onboard, bringing a new population with them. In 2015, we had over 5 million people use our apps, with over 1 million documents lodged electronically. Working closely with Australia Post, we have stopped sending printed letters for a range of transactions. Instead, we send recipients a message to their myGov inbox.

So, what are the main lessons in embracing digital transformation and improving customer experiences? The first is to develop a culture of rapid innovation and experimentation. If you try to precisely design and prescribe everything in the digital world, it just won't stick. Instead, you've got to get out fast, have a go, iterate, try things, break things, throw them away and start again. Because until you actually get out there and start using things, you won't even know what the problems you face will be.

The second key lesson for us in our bid to digitise is to have one digital team. We rejected the notion of having a separate information and communications technology (ICT) business, and instead established a united digital team. Previously, the way we were working as a business was either to throw a pig over the fence and hope ICT caught it, or do some new flash thing where integrated business requirements were the cool tool-adding wings to the pig so that it landed more softly. But then some of my colleagues in the room would inevitably ask: why is there a fence? In other words: why don't we build one team, combine project teams, business, ICT and customers and redesign our digital products? So we started doing that, and our results have improved as a consequence. 
The third lesson is to act across government. By that I mean reframe the way you think so that you start to enable a whole new across-government capability. For example, we got together with the ATO in 2013; there would have been about 70 Senior Executive Service (SES) staff in the room, we were organised into service channels and policy groups. We were sharing information, trying to look for points of intersection. We got to midday and we thought, 'this is a disaster, we're never going to find a point of intersection'. We reframed the afternoon to look at life events and to look at individual journeys; we looked at a small business and thought, 'wow, look at these points of intersection where we make people bounce in between us, let's see if we can change that'.

The integrated shopfront offer came out of that, as did myGov at the front end.

To give you some perspective, our technology platform in DHS was invented about the same time as Pacman-the same era as the cassette. Not many people nowadays would have a cassette in their ownership. Yet at DHS, we are still running cassettes: they run our payment system. At 30 years old, they are a reliable workhorse but not agile. But you know government: ask for a change, and nine months and $\$ 8$ million later they will get back to you with a result. And so we are not really in a position with a platform that enables agile service delivery, let alone policy delivery.

When we started, the system that we built paid out $\$ 10$ billion a year and touched around 2.5 million Australians. Nowadays, it pays out over $\$ 100$ billion a year, meaning that it needs updating beyond simply the proverbial new lick of paint. And so rather than pour the same old wine into a new bottle, we decided we would completely rethink what the business model would need to be to support government going forward. A couple of key outcomes emerged.

The first is that government can no longer invest in an agency to replace its system for only its benefit. We moved the whole business case into the mode of 'this is a utility for government': it is owned by government and it will need to produce a payment functionality that can be used across all tiers of government-and, I would even propose, across nongovernment organisations. In other words, government shouldn't build its own payment system for people simply because it is responsible for 
giving out incentives. Rather, it should use ours and just front it. The idea of government as a platform-now this is one of the platforms we want to build.

The other issues are being able to move more quickly and deliver on government policy. We are working in three-month cycles, data in real time and real-time reporting. Traditionally, one of the issues we have is that if government asks us a policy question and want the data, we are a little like Sir Humphrey in Yes, Minister: by the time we can come back with an answer, the issue is irrelevant. But in the near future we will be able to get real-time access to data, which currently takes a lot of effort.

In summary, to shift from being a siloed agency like Centrelink, Medicare or DHS to becoming an integrated agency that can provide a platform upon which government can deliver a range of services, we had to reframe our thinking before we got to improving the technology. And so, right at the start of the process, we put down our pens and ring binders, banned paper and put all the agencies in the room and said: 'why don't you co-design the investment proposition with us?'

As a consequence, when we went to cabinet, each one of the six outcomes for this investment were owned by different ministers. It was so successful we decided we should keep running the whole program like this. And although it is in many respects life events-driven, we had to pull back and create the platform to reframe the thinking around how we might approach this issue; hopefully, when we get down to the actual doing, that's what we'll build. But we didn't wait until the building stage to consider how to get government to function as a platform and have the lovely people from Sysco and Telstra tell us this isn't how you do it. Because the only way to stop silos from forming is if you address policy issues up front. In conclusion, we have moved from a relationship with our colleagues at the Department of Social Services, from ring binders of documents and committee rooms, to working in a collaborative space in order to redesign how we are going to make payments in Australia in the future. It has been quite transformative. 
This text is taken from Opening Government: Transparency and Engagement in the Information Age, edited by John Wanna and Sam Vincent, published 2018 by ANU Press, The Australian National University, Canberra, Australia.

doi.org/10.22459/OG.04.2018.13 